\title{
The neurobiological basis of ADHD
}

\author{
Paolo Curatolo*, Elisa D’Agati, Romina Moavero
}

\begin{abstract}
Attention-Deficit/Hyperactivity Disorder is not a single pathophysiological entity and appears to have a complex etiology. There are multiple genetic and environmental risk factors with small individual effect that act in concert to create a spectrum of neurobiological liability. Structural imaging studies show that brains of children with Attention-Deficit/Hyperactivity Disorder are significantly smaller than unaffected controls. The prefrontal cortex, basal ganglia and cerebellum are differentially affected and evidence indicating reduced connectivity in white matter tracts in key brain areas is emerging. Genetic, pharmacological, imaging, and animal models highlight the important role of dopamine dysregulation in the neurobiology of Attention-Deficit/Hyperactivity Disorder. To date, stimulants are the most effective psychopharmacological treatments available for Attention-Deficit/Hyperactivity Disorder. Currently only immediate release methylphenidate and atomoxetine are approved for the treatment of ADHD in Italy. Drug treatment should always be part of a comprehensive plan that includes psychosocial, behavioural and educational advice and interventions.
\end{abstract}

\section{Introduction}

Attention-Deficit/Hyperactivity Disorder (ADHD) is a common, long-lasting, treatable childhood psychiatric disorder, characterised by a pattern of developmentally inappropriate inattention, motor restlessness, and impulsivity that affects approximately $3-7 \%$ of school-aged children [1].

ADHD was first recognised 100 years ago as a childhood disorder found mainly in boys, and was initially described as "hyperactivity" or "hyperkinetic disorder of childhood". This abnormal behaviour was found to be the result of a biological condition rather than a result of poor parenting [2]. In the 1960's and 70's much of the focus on what is now called ADHD was on hyperactivity. The presence of excessive movements in children was proposed to result from bilateral cortical activity secondary to a lack of transcallosal fibre tract-mediated interhemispheric inhibition [3]. Attention Deficit Disorder with or without Hyperactivity first featured in DSM-III in 1980 [4], and the more recent DSM-IV-TR provided updated ADHD criteria [5]. For a diagnosis of ADHD, symptoms need to occur often, have persisted for the past six months, and be maladaptive and incongruent with the individual's developmental level. Additionally, an ADHD diagnosis is only given if at least

\footnotetext{
* Correspondence: curatolo@uniroma2.it

* Correspondence: curatolo@uniroma2.it University of Rome, Italy
}

some of the behavioural symptoms were present before the age of 7 years, occur in more than one setting, and cause significant impairment in social and school functioning.

The renaming of the disorder, the subsequent focus on attention, and the clarification of three subtypes led to a range of neurocognitive and neurobiological hypotheses regarding the etiology and pathophysiology of ADHD within a more specific brain localisation. Furthermore, neurocognitive models of ADHD have become more refined, and one particular executive process, inhibition, is now considered to be a core deficit [6].

Current theories emphasise the central role of attentional and executive dysfunctions in children $[7,8]$, as well as affective components involving emotional control and motivational processes [9]. A growing body of evidence supports a model in which multiple genetic and environmental factors interact during early development to create a neurobiological susceptibility to the disorder; the expression of which is mediated by alterations within different and diverse neural networks and deficits in the neuropsychological functions that these subserve [10]. Individuals with ADHD present difficulties in several domains of attentional and cognitive functions: problem solving, planning, orienting, alerting, cognitive flexibility, sustained attention, response inhibition, and working memory $[7,11]$. Other domains involving affective components, such as motivation and delay aversion, are also 
affected $[8,9]$. Motor difficulties, such as problems with sensory motor coordination, including poor handwriting, clumsiness, and marked delays in achieving motor milestones [12], have also been reported and the prevalence of motor impairment in the ADHD population has been estimated to be approximately 50\% [13]. Motor problems might be partially related to abnormalities in structure and/or function of the cerebellum and basal ganglia found in ADHD [14].

Recently, neuroimaging has led to several important advances in the understanding of the neurobiology underlying the clinical picture of ADHD, and demonstrates a clear brain basis to the disorder in regions involved in attention, and executive and inhibitory control $[15,16]$. Furthermore, transcranial magnetic stimulation (TMS) has provided evidence that intracortical inhibition, as indexed by the immature ipsilateral motor cortex, normalises with psychostimulant treatment [17]. There is an exciting confluence between emerging studies in basic neurobiology and the genetic, neuroimaging, and neuropsychological analyses of ADHD. Knowledge of neurobiology can offer child neurologists, psychiatrists and other healthcare professionals a valuable framework for the interpretation of clinical findings of children meeting the criteria for diagnosis of ADHD. In this article we provide a brief overview of the salient neurological basis of the disorder.

\section{Etiology}

ADHD is not a single pathophysiological entity and appears to have a complex etiology. Multiple genetic and environmental factors act together to create a spectrum of neurobiological liability.

\section{The genetic basis for ADHD}

Genetic factors are implicated in ADHD, but the mechanism of action is not completely understood. Twin, family and adoption studies of ADHD have supported a strong genetic contribution to the disorder, with heritability ranging from $60-90 \%[18,19]$.

Genes regulating neurotransmitter systems have been implicated in ADHD. Candidate gene studies of ADHD have produced substantial evidence implicating several genes in the etiology of the disorder, with meta-analyses supportive of a role of the genes coding for DRD4, DRD5, SLC6A3, SNAP-25, and HTR1B [20]. Genome scan studies on potential alleles for ADHD have demonstrated linkage on chromosomes 5p13, 6q12, 16p13, $17 \mathrm{p} 11$ and $11 \mathrm{q} 22-25$ [21,22]. However, genome-wide association studies have failed to report any associations that are significant after correction for multiple testing [23]. Therefore, a plausible genetic hypothesis for ADHD is a mixture of dominant and recessive major genes that act with complex polygenic transmission patterns [18]. An increased rate of large, rare, chromosomal deletions and duplications known as copy number variants have been reported in individuals with ADHD [24]. However, genetic testing in an individual child is not currently practical in normal clinical practise.

Sometimes ADHD-like symptoms are exhibited by patients with established neurogenetic disorders such as Tuberous Sclerosis Complex, Neurofibromatosis I, Turner Syndrome, Williams Syndrome, Velocardiofacial syndrome, Prader-Willy syndrome, and Fragile $\times$ Syndrome. Although each syndrome may arise from different genetic abnormalities with multiple molecular functions, the effects of these abnormalities may give rise to common effects downstream in the biological pathways or neural circuits, resulting in the presentation of ADHD symptoms [25].

\section{The environmental basis of ADHD}

Pre-, peri- and postnatal environmental factors play an important role in the pathogenesis of ADHD. Prenatal factors are associated with maternal lifestyle during pregnancy. For example, prenatal alcohol exposure is known to induce brain structural anomalies, especially in the cerebellum [26]. Children exposed prenatally to alcohol can become hyperactive, disruptive, impulsive, and are at an increased risk of a range of psychiatric disorders $[27,28]$. Maternal smoking produces a 2.7 -fold increased risk for ADHD [29], and a dose-response relationship between maternal smoking during pregnancy and hyperactivity has been reported [30]. This may be due to an effect on nicotinic receptors, which modulate dopaminergic activity. Dopaminergic disruption is believed to be involved in the pathophysiology of ADHD [31,32].

Peri-natal factors have also been implicated, with a two-fold increase in ADHD in very low-birthweight children and an increased rate of pregnancy and birth complications in mothers of children later diagnosed with ADHD [33].

Among postnatal factors, a role for malnutrition and dietary deficiency in ADHD has been proposed. An imbalance of essential fatty acid (omega-3 and omega-6) intake has been suggested to be potentially involved in the development of ADHD [34], although further evidence is required to establish a role. Iron deficiency has been implicated in some cases [35]. Early deprivation of social environment during the postnatal period may also have significant effects.

\section{Gene-environment interactions}

More complex models of the etiology of ADHD incorporating gene-environment interplay need to be considered. Recent studies have focused on the joint effects of gene variants (of DRD4 and DAT1) and prenatal 
substance exposures on subtypes of ADHD children, demonstrating that smoking during pregnancy is associated with the combined ADHD type in genetically susceptible children [36]. A significant interaction between DAT1 genotype and prenatal smoke exposure was found in males. Men homozygous for the DAT1 10-repeat allele had higher hyperactivity-impulsivity than males from all other groups [37]. Despite the heterogeneity of the etiology and pathophysiology of ADHD, abnormal DAT density seems to be common among subjects with ADHD [38].

\section{Neuroimaging}

Growing evidence points to the involvement of the frontostriatal network as a likely contributor to the pathophysiology of ADHD. This network involves the lateral prefrontal cortex, the dorsal anterior cingulate cortex, and the caudate nucleus and putamen. In ADHD patients, reductions in volume have been observed in total cerebral volume, the prefrontal cortex, the basal ganglia (striatum), the dorsal anterior cingulate cortex, the corpus callosum and the cerebellum [39]. A developmental trajectories study in ADHD patients showed a delay in cortical maturation, and demonstrated that different clinical outcomes may be associated with different developmental trajectories in adolescence and beyond [40]. In studies of cortical development in children with ADHD, a marked delay in brain maturation was seen; the grey matter peaks were about 3 years later than in healthy controls [41]. The delay was most prominent in prefrontal regions important in the control of cognitive processes including attention and motor planning $[41,42]$. Compensatory networks including basal ganglia, insula and cerebellum have been implicated for relative lower cognitive load tasks in ADHD patients [43].

Neuroimaging studies have also reported reduced white matter (WM) volumes [43], midsagittal corpus callosum (CC) areas [44], and cortical thickness [43] in ADHD patients compared with controls. One of the most replicated alterations is a significantly smaller CC, but there are conflicting reports regarding the affected callosal segments [45]. Recent magnetic resonance imaging (MRI) structural investigations have shown that WM alterations are present in children, adolescents and adults with ADHD [46]. In 15 young males with ADHD, Silk et al. (2008) found WM abnormalities in several distinct regions underlying the inferior parietal, occipito-parietal, inferior frontal, and inferior temporal cortex [47]. Tractography methods showed that these regions form part of WM pathways connecting prefrontal and parieto-occipital areas with the striatum and the cerebellum. The authors also demonstrated anomalous WM development in ADHD in distinct cortical regions that they had previously shown to be dysfunctional or hypoactive in a functional MRI study of subjects with ADHD [47].

Diffusion tensor imaging (DTI) is an MRI modality that provides information about the direction and integrity of neural fibre tracks in the brain in vivo. DTI studies have revealed developmental changes in cortical WM pathways in prefrontal regions and in pathways surrounding the basal ganglia and cerebellum in patients with ADHD, which presumably reflect decreasing myelination of axons. It is believed that these changes cause a decrease in the speed of neuronal communication [48]. Moreover, the neural networks serving the corticostriatal and corticocerebellar circuits could represent putative biomarkers for ADHD. Indeed, in this disorder their quantification using DTI could be relevant for both diagnostic and therapeutic purposes [46].

As well as offering new data to map the brain systems involved in ADHD, and to integrate these findings with clinical symptoms, functional neuroimaging studies allow us to understand the mechanisms of treatment response $[42,49]$. Positron emission tomography (PET) studies have shown that methylphenidate hydrochloride $(\mathrm{MPH})$ blocks dopamine active transporters (DAT) and that extracellular dopamine (DA) increases in proportion to the level of blockade and to the rate of DA release. This process is associated with an enhanced perception of the external stimulus as salient in subjects with ADHD [50].

\section{Clinical diagnosis and comorbidities}

Clinical presentation of ADHD may vary according to age and stage of development and there are cultural differences in the level of activity and inattention that are regarded as a problem [51]. Diagnosis requires that there should be clear evidence of clinically significant impairment in social, academic, or occupational functioning [5]. The predominantly inattentive type is relatively more common in females. Children with the predominantly hyperactive-impulsive type are aggressive and impulsive, and tend to be highly rejected by their peers. The combined type causes more impairment in global functioning, in comparison with the other two types. Adolescents with ADHD often report low selfesteem and poor peer relationships; and are at high risk of smoking and substance abuse early in life [52,53].

Endophenotypes can be used as trait markers for disease susceptibility, to identify more genetically homogeneous subgroups, to highlight distinct pathophysiological mechanisms or etiological pathways, or to define "spectrum" phenotypes suitable for quantitative trait analyses [54]. Cognitive deficits and motor response inhibition are the prime endophenotype candidates in ADHD [55].

The co-existence of several other types of psychopathology along with ADHD, such as oppositional defiant 
disorder, mood and anxiety disorders, learning disorders, tics, and mental retardation, is very common [56].

\section{Treatment}

Before starting treatment, it is important to identify the target outcomes to guide the therapy decision. Drug treatment should be based on a thorough assessment and should always be part of a comprehensive treatment plan that includes psychosocial, behavioural, and educational advice and interventions. Psychotherapy combined with medication may play a role in treating behavioural problems, organisational issues and psychiatric comorbidities [57]. In Italy, an ADHD diagnosis can only be made at a regional referral centre approved by the Italian Ministry of Health. Treatment guidelines put forward by the Ministry of Health and based on European guidelines, specify that pharmacological treatment can only be initiated after failure of cognitive behavioural therapy over a period of 6 months or longer has been demonstrated. Patients must first be enrolled in the ADHD medication registry before treatment with MPH or atomoxetine (ATX) can be prescribed.

Behavioural therapy and pharmacological treatment have both been shown to benefit ADHD patients. A longitudinal study of the efficacy of different treatments (an intensively monitored medication program, behavioural therapy, combination of medication and behavioural therapy or treatment as usual by community care) showed after 8-year follow-up that all four of the original treatment groups had a similar outcome: all showed improvement in comparison with pretreatment baseline scores, but none demonstrated superiority [58].

The fronto-subcortical circuits (lateral prefrontal cortex, dorsal anterior cingulate cortex, caudate, and putamen) associated with ADHD are rich in catecholamines, which are involved in the mechanism of action of medications used to treat this disorder. Neuropharmacological studies have provided evidence that ADHD involves dysregulation of both noradrenaline (NE) and DA neurotransmitter systems [59]. MPH treatment causes an increase in DA signalling through multiple actions, including blockade of the DA reuptake transporter, amplification of DA response duration, disinhibition of the dopamine D2 receptor and amplification of DA tone [60]. MPH is also an inhibitor of NE re-uptake. ATX is a selective inhibitor of synaptic re-uptake, and in vivo, it specifically increases extracellular levels of DA in the prefrontal cortex but not in the striatum; probably by modulating cortical synaptic DA uptake via the NE transporter [61]. Dextroamphetamine increases the synaptic activity of DA and NE by increasing the release of the neurotransmitters into the synaptic cleft, decreasing reuptake back into the presynaptic neuron, and inhibiting their catabolism [62]. Strong evidence exists indicating that stimulant medications, such as MPH and dextroamphetamine, and the non-stimulant ATX, are effective in improving ADHD symptoms [63]. Guanfacine is a selective alpha2A adrenergic receptor agonist, which improves working memory by stimulating postsynaptic alpha2A adrenoceptors, strengthening the functional connectivity of prefrontal cortex networks [64]. Guanfacine has also been shown to be effective in reducing ADHD symptoms $[65,66]$. Table 1 summarises the most important characteristics of these pharmacological treatments for ADHD. Only ATX and immediate release $\mathrm{MPH}$ are currently approved for the treatment of ADHD in Italy.

ADHD pharmacological therapies are generally welltolerated (Table 1). However, concerns surrounding the cardiovascular safety of some of these drugs has prompted a recent examination of the effects of ATX and $\mathrm{MPH}$ on blood pressure (BP), heart rate (HR), and ECG parameters. MPH appears to cause minor increases in BP and HR, with no strong data to suggest that itincreases the QT interval. Limited data suggest that ATX may increase BP and HR in the short term; in the long term it appears to only increase BP. The effects of ATX on QT interval remain uncertain. Because the current evidence is based on research that has not been specifically designed to investigate the cardiovascular effects of these drugs, it is difficult to draw firm conclusions [67].

Both MPH and ATX significantly increase activation in key cortical and subcortical regions subserving attention and executive functions. Therefore, alterations in dopaminergic and noradrenergic function are apparently necessary for the clinical efficacy of pharmacological treatment of ADHD [68]. However MPH and ATX have both common and distinct neural effects, consistent with the observation that while many children respond well to both treatments, some respond preferentially to one or the other. Although pharmacotherapy for ADHD appears to prepare and facilitate the brain for learning, experiential programs need to elicit compensatory development in the brain. The clinical amelioration of some children after environmental experiential inputs and early cognitive/behavioural treatment could indicate outcome-associated plastic brain response [69]. One year of treatment with MPH may be beneficial to show enduring normalisation of neural correlates of attention. However, little is known about the long-term effects of stimulants on the functional organisation of the developing brain [70]. Recent findings have shown that chronic MPH use in drug-naive boys with ADHD enhanced neuropsychological functioning on "recognition memory" component tasks with modest executive demands [71]. Patients receiving pharmacological treatment for ADHD should always be closely monitored for 
Table 1 Clinical characteristics of ADHD pharmacotherapies

\begin{tabular}{|c|c|c|c|c|}
\hline Pharmacotherapy & Molecular mechanisms [59-66] & Formulations & $\begin{array}{c}\text { Efficacy } \\
\text { (meta-analysis effect } \\
\text { size) }[74,70]\end{array}$ & $\begin{array}{c}\text { Common adverse events } \\
{[75-79]}\end{array}$ \\
\hline \multicolumn{5}{|l|}{ Stimulants } \\
\hline \multirow[t]{6}{*}{ Methylphenidate } & $\begin{array}{c}\text { Blocks DA reuptake transporter, } \\
\text { amplifies DA response duration, } \\
\text { disinhibits D2 receptor, inhibits NE } \\
\text { re-uptake }\end{array}$ & Immediate release & $0.92(0.80,1.05)$ & $\begin{array}{l}\text { Decreased appetite, insomnia, } \\
\text { abdominal pain, headache dizziness, } \\
\text { reduced weight gain, affective } \\
\text { symptoms }\end{array}$ \\
\hline & & Osmotic release & $0.90(0.76,1.05)$ & $\begin{array}{c}\text { Decreased appetite, abdominal pain, } \\
\text { headache }\end{array}$ \\
\hline & & Extended release & $0.85(0.65,1.05)$ & $\begin{array}{l}\text { Decreased appetite, headache, } \\
\text { abdominal pain }\end{array}$ \\
\hline & & Long-acting & $0.96(0.75,1.16)$ & $\begin{array}{c}\text { Headache, insomnia, upper } \\
\text { abdominal pain, decreased appetite, } \\
\text { anorexia }\end{array}$ \\
\hline & & Transdermal patch & Not available & Appetite, nausea, vomiting, insomnia \\
\hline & & Dexmethylphenidate & $0.76(0.45,1.08)$ & $\begin{array}{l}\text { Decreased appetite, headache, } \\
\text { abdominal pain, nausea }\end{array}$ \\
\hline \multirow[t]{3}{*}{ Dextroamphetamine } & $\begin{array}{c}\text { Increases release of DA and NE into } \\
\text { synaptic cleft, decreases reuptake } \\
\text { into presynaptic neuron, inhibits } \\
\text { catabolism }\end{array}$ & Immediate release & $1.24(0.88,1.60)$ & Decreased appetite, insomnia \\
\hline & & Extended release & $1.13(0.57,1.69)$ & $\begin{array}{l}\text { Palpitations, tremor, insomnia, } \\
\text { decreased appetite, headache, } \\
\text { dizziness, dry mouth, weight loss, } \\
\text { abdominal symptoms }\end{array}$ \\
\hline & & Prodrug & $1.52(1.34,1.71)$ & $\begin{array}{c}\text { Decreased appetite, headache, } \\
\text { insomnia, abdominal pain, irritability }\end{array}$ \\
\hline \multirow[t]{2}{*}{$\begin{array}{l}\text { Mixed } \\
\text { amphetamine salts }\end{array}$} & $\begin{array}{l}\text { Increases release of DA and NE into } \\
\text { synaptic cleft, decreases reuptake } \\
\text { into presynaptic neuron, inhibits } \\
\text { catabolism }\end{array}$ & Immediate release & $1.34(0.95,1.72)$ & $\begin{array}{c}\text { Decreased appetite, agitation, } \\
\text { insomnia }\end{array}$ \\
\hline & & Extended release & $0.77(0.59,0.94)$ & $\begin{array}{l}\text { Decreased appetite, headache, } \\
\text { insomnia }\end{array}$ \\
\hline \multicolumn{5}{|l|}{ Non-stimulants } \\
\hline Atomoxetine & $\begin{array}{l}\text { Selectively inhibits synaptic } \\
\text { DA re-uptake }\end{array}$ & Immediate release & $0.63(0.57,0.69)$ & $\begin{array}{l}\text { Upper abdominal pain, decreased } \\
\text { appetite, vomiting, somnolence, } \\
\text { irritability, fatigue }\end{array}$ \\
\hline \multirow[t]{2}{*}{ Guanfacine } & $\begin{array}{l}\text { Selective alpha2A adrenergic } \\
\text { receptor agonist }\end{array}$ & Immediate release & Not available & $\begin{array}{l}\text { Sedation, insomnia, decreased } \\
\text { appetite, dry mouth, constipation }\end{array}$ \\
\hline & & Extended release & $0.8(0.53,1.07)$ & $\begin{array}{l}\text { Somnolence, fatigue, upper } \\
\text { abdominal pain, sedation }\end{array}$ \\
\hline
\end{tabular}

both common and unusual potentially severe adverse effects.

\section{Conclusions}

Convergent data from neuroimaging, neuropsychology, genetics and neurochemical studies consistently point to the involvement of the frontostriatal network as a likely contributor to the pathophysiology of ADHD. This network involves the lateral prefrontal cortex, the dorsal anterior cingulate cortex and the caudate nucleus and putamen [39]. Functional neuroimaging has provided new ways to examine the pathophysiology of ADHD, has shown widespread dysfunction in neural systems involving the prefrontal, striatal, and parietal brain regions, and has led to a brain model of deficits in multiple developmental pathways [72]. Molecular genetic studies support dysregulation of neurotransmitter systems as the basis of genetic susceptibility to the disorder, and it is becoming clear that the genotype may influence the response to medications [73]. Hopefully, advances in understanding the underlying neurobiology of ADHD will contribute to identifying more specific and targeted pharmacotherapies, and will help child neurologists to better manage their patients.

\section{Acknowledgements}

Editing of the manuscript and table preparation was performed by Rachel Wright of Fishawack Communications, supported by Shire Development Inc. 


\section{Authors' contributions}

PC proposed and designed the study, and revised the final draft. EDA and RM reviewed all the relevant articles on the literature, and prepared the first draft under the supervision of Prof. Paolo Curatolo. All authors contributed to the intellectual content and approved the final version.

\section{Competing interests}

Professor Paolo Curatolo has served as an Advisory Board Member for Eli Lilly and Shire, and has received research grants from Eli Lilly and Shire. The other authors have no conflicts of interest to declare.

Received: 3 November 2010 Accepted: 22 December 2010

Published: 22 December 2010

\section{References}

1. Polanczyk G, de Lima MS, Horta BL, Biederman J, Rohde LA: The worldwide prevalence of ADHD: a systematic review and metaregression analysis. Am J Psychiatry 2007, 164:942-948.

2. Still G: The Coulstonian lectures on some abnormal physical conditions in children. Lecture 1. Lancet 1902, 1008-1012, 1077-1082, 1163-1168.

3. Denckla MB, Rudel RG: Anomalies of motor development in hyperactive boys. Ann Neurol 1978, 3:231-233.

4. American Psychiatric Association: Diagnostic and Statistical Manual of Mental Disorders. 3 (DSM-III) edition. Washington: American Psychiatric Association; 1980.

5. APA: Diagnostic and Statistical Manual of Mental Disorders. Fourth, Text Revision edn. Washington 2000.

6. Barkley RA: Behavioral inhibition, sustained attention, and executive functions: constructing a unifying theory of ADHD. Psychol Bull 1997, 121:65-94.

7. Sergeant JA, Geurts H, Huijbregts S, Scheres A, Oosterlaan J: The top and the bottom of ADHD: a neuropsychological perspective. Neurosci Biobehav Rev 2003, 27:583-592.

8. Castellanos FX, Sonuga-Barke EJ, Milham MP, Tannock R: Characterizing cognition in ADHD: beyond executive dysfunction. Trends Cogn Sci 2006, 10:117-123.

9. Nigg JT, Casey BJ: An integrative theory of attention-deficit/hyperactivity disorder based on the cognitive and affective neurosciences. Dev Psychopathol 2005, 17:785-806.

10. Sonuga-Barke EJ, Halperin JM: Developmental phenotypes and causal pathways in attention deficit/hyperactivity disorder: potential targets for early intervention? J Child Psychol Psychiatry 51:368-389.

11. Pasini A, Paloscia C, Alessandrelli R, Porfirio MC, Curatolo P: Attention and executive functions profile in drug naive ADHD subtypes. Brain Dev 2007, 29:400-408.

12. Piek JP, Pitcher TM, Hay DA: Motor coordination and kinaesthesis in boys with attention deficit-hyperactivity disorder. Dev Med Child Neurol 1999, 41:159-165.

13. Racine $M B$, Majnemer $A$, Shevell $M$, Snider L: Handwriting performance in children with attention deficit hyperactivity disorder (ADHD). J Child Neurol 2008, 23:399-406.

14. Pasini A, D'Agati E: Pathophysiology of NSS in ADHD. World J Biol Psychiatry 2009, 10:495-502.

15. Curatolo P: The neurology of attention deficit/hyperactivity disorder. Brain Dev 2005, 27:541-543.

16. Suskauer SJ, Simmonds DJ, Fotedar S, Blankner JG, Pekar JJ, Denckla MB, Mostofsky SH: Functional magnetic resonance imaging evidence for abnormalities in response selection in attention deficit hyperactivity disorder: differences in activation associated with response inhibition but not habitual motor response. J Cogn Neurosci 2008, 20:478-493.

17. Hoeppner J, Wandschneider R, Neumeyer M, Gierow W, Haessler F, Herpertz SC, Buchmann J: Impaired transcallosally mediated motor inhibition in adults with attention-deficit/hyperactivity disorder is modulated by methylphenidate. J Neural Transm 2008, 115:777-785.

18. Sharp SI, McQuillin A, Gurling HM: Genetics of attention-deficit hyperactivity disorder (ADHD). Neuropharmacology 2009, 57:590-600

19. Gizer IR, Ficks C, Waldman ID: Candidate gene studies of ADHD: a metaanalytic review. Hum Genet 2009, 126:51-90.

20. Faraone SV, Mick E: Molecular genetics of attention deficit hyperactivity disorder. Psychiatr Clin North Am 33:159-180.
21. Ogdie MN, Fisher SE, Yang M, Ishii J, Francks C, Loo SK, Cantor RM, McCracken JT, McGough JJ, Smalley SL, Nelson SF: Attention deficit hyperactivity disorder: fine mapping supports linkage to $5 p 13,6 q 12$, 16p13, and 17p11. Am J Hum Genet 2004, 75:661-668.

22. Coghill D, Banaschewski T: The genetics of attention-deficit/hyperactivity disorder. Expert Rev Neurother 2009, 9:1547-1565.

23. Franke B, Vasquez AA, Johansson S, Hoogman M, Romanos J, BoreattiHummer A, Heine M, Jacob CP, Lesch KP, Casas M, et al: Multicenter Analysis of the SLC6A3/DAT1 VNTR Haplotype in Persistent ADHD Suggests Differential Involvement of the Gene in Childhood and Persistent ADHD. Neuropsychopharmacology 2009, 35(3):656-64.

24. Williams NM, Zaharieva I, Martin A, Langley K, Mantripragada K, Fossdal R, Stefansson H, Stefansson K, Magnusson P, Gudmundsson OO, et al: Rare chromosomal deletions and duplications in attention-deficit hyperactivity disorder: a genome-wide analysis. Lancet 2010, 376(9750):1401-8.

25. Lo-Castro A, D'Agati E, Curatolo P: ADHD and genetic syndromes. Brain Dev 2010.

26. Coffin JM, Baroody S, Schneider K, O'Neill J: Impaired cerebellar learning in children with prenatal alcohol exposure: a comparative study of eyeblink conditioning in children with ADHD and dyslexia. Cortex 2005, 41:389-398.

27. D'Onofrio BM, Van Hulle CA, Waldman ID, Rodgers $J$, Rathouz PJ, Lahey BB: Causal inferences regarding prenatal alcohol exposure and childhood externalizing problems. Arch Gen Psychiatry 2007, 64:1296-1304.

28. Sen B, Swaminathan S: Maternal prenatal substance use and behavior problems among children in the U.S. J Ment Health Policy Econ 2007, 10:189-206.

29. Milberger S, Biederman J, Faraone SV, Chen L, Jones J: Is maternal smoking during pregnancy a risk factor for attention deficit hyperactivity disorder in children? Am J Psychiatry 1996, 153:1138-1142.

30. Kotimaa AJ, Moilanen I, Taanila A, Ebeling H, Smalley SL, McGough JJ, Hartikainen AL, Jarvelin MR: Maternal smoking and hyperactivity in 8year-old children. J Am Acad Child Adolesc Psychiatry 2003, 42:826-833.

31. Potter AS, Newhouse PA, Bucci DJ: Central nicotinic cholinergic systems: a role in the cognitive dysfunction in attention-deficit/hyperactivity disorder? Behav Brain Res 2006, 175:201-211.

32. Weiss S, Tzavara ET, Davis RJ, Nomikos GG, Michael Mclntosh J, Giros B, Martres MP: Functional alterations of nicotinic neurotransmission in dopamine transporter knock-out mice. Neuropharmacology 2007, 52:1496-1508.

33. Taylor E, Rogers JW: Practitioner review: early adversity and developmental disorders. J Child Psychol Psychiatry 2005, 46:451-467.

34. Raz R, Gabis L: Essential fatty acids and attention-deficit-hyperactivity disorder: a systematic review. Dev Med Child Neurol 2009, 51:580-592.

35. Juneja M, Jain R, Singh V, Mallika V: Iron Deficiency in Indian Children with Attention Deficit Hyperactivity Disorder. Indian Pediatr 2010, 47(11):955-8.

36. Neuman RJ, Lobos E, Reich W, Henderson CA, Sun LW, Todd RD: Prenatal smoking exposure and dopaminergic genotypes interact to cause a severe ADHD subtype. Biol Psychiatry 2007, 61:1320-1328.

37. Becker K, El-Faddagh M, Schmidt MH, Esser G, Laucht M: Interaction of dopamine transporter genotype with prenatal smoke exposure on ADHD symptoms. J Pediatr 2008, 152:263-269.

38. Spencer TJ, Biederman J, Madras BK, Faraone SV, Dougherty DD, Bonab AA, Fischman AJ: In vivo neuroreceptor imaging in attention-deficit/ hyperactivity disorder: a focus on the dopamine transporter. Biol Psychiatry 2005, 57:1293-1300.

39. Emond V, Joyal C, Poissant H: [Structural and functional neuroanatomy of attention-deficit hyperactivity disorder (ADHD)]. Encephale 2009, 35:107-114.

40. Shaw P, Rabin C: New insights into attention-deficit/hyperactivity disorder using structural neuroimaging. Curr Psychiatry Rep 2009, 11:393-398.

41. Shaw P, Lerch J, Greenstein D, Sharp W, Clasen L, Evans A, Giedd J, Castellanos FX, Rapoport J: Longitudinal mapping of cortical thickness and clinical outcome in children and adolescents with attention-deficit/ hyperactivity disorder. Arch Gen Psychiatry 2006, 63:540-549.

42. Shaw P, Eckstrand K, Sharp W, Blumenthal J, Lerch JP, Greenstein D, Clasen L, Evans A, Giedd J, Rapoport JL: Attention-deficit/hyperactivity 
disorder is characterized by a delay in cortical maturation. Proc Natl Acad Sci USA 2007, 104:19649-19654.

43. Castellanos FX, Lee PP, Sharp W, Jeffries NO, Greenstein DK, Clasen LS, Blumenthal JD, James RS, Ebens CL, Walter JM, et al: Developmental trajectories of brain volume abnormalities in children and adolescents with attention-deficit/hyperactivity disorder. JAMA 2002, 288:1740-1748.

44. Krain AL, Castellanos FX: Brain development and ADHD. Clin Psychol Rev 2006, 26:433-444.

45. Luders E, Narr KL, Hamilton LS, Phillips OR, Thompson PM, Valle JS, Del'Homme M, Strickland T, McCracken JT, Toga AW, Levitt JG: Decreased callosal thickness in attention-deficit/hyperactivity disorder. Biol Psychiatry 2009, 65:84-88.

46. Makris N, Buka SL, Biederman J, Papadimitriou GM, Hodge SM, Valera EM, Brown AB, Bush G, Monuteaux MC, Caviness VS, et al: Attention and executive systems abnormalities in adults with childhood ADHD: A DTMRI study of connections. Cereb Cortex 2008, 18:1210-1220.

47. Silk TJ, Vance A, Rinehart N, Bradshaw JL, Cunnington R: White-matter abnormalities in attention deficit hyperactivity disorder: A diffusion tensor imaging study. Hum Brain Mapp 2009, 30(9):2757-65a.

48. D'Agati E, Casarelli L, Pitzianti MB, Pasini A: Overflow movements and white matter abnormalities in ADHD. Prog Neuropsychopharmacol Biol Psychiatry 34:441-445.

49. Bush G, Spencer TJ, Holmes J, Shin LM, Valera EM, Seidman LJ, Makris N, Surman C, Aleardi M, Mick E, Biederman J: Functional magnetic resonance imaging of methylphenidate and placebo in attention-deficit/ hyperactivity disorder during the multi-source interference task. Arch Gen Psychiatry 2008, 65:102-114.

50. Volkow ND, Wang GJ, Fowler JS, Ding YS: Imaging the effects of methylphenidate on brain dopamine: new model on its therapeutic actions for attention-deficit/hyperactivity disorder. Biol Psychiatry 2005, 57:1410-1415.

51. Taylor E, Dopfner M, Sergeant J, Asherson P, Banaschewski T, Buitelaar J, Coghill D, Danckaerts M, Rothenberger A, Sonuga-Barke E, et al: European clinical guidelines for hyperkinetic disorder - first upgrade. Eur Child Adolesc Psychiatry 2004, 13(Suppl 1):17-30.

52. Elkins IJ, McGue M, lacono WG: Prospective effects of attention-deficit/ hyperactivity disorder, conduct disorder, and sex on adolescent substance use and abuse. Arch Gen Psychiatry 2007, 64:1145-1152.

53. Loe IM, Feldman HM: Academic and educational outcomes of children with ADHD. J Pediatr Psychol 2007, 32:643-654.

54. Crosbie J, Perusse D, Barr CL, Schachar RJ: Validating psychiatric endophenotypes: inhibitory control and attention deficit hyperactivity disorder. Neurosci Biobehav Rev 2008, 32:40-55.

55. Goos LM, Crosbie J, Payne S, Schachar R: Validation and extension of the endophenotype model in ADHD patterns of inheritance in a family study of inhibitory control. Am J Psychiatry 2009, 166:711-717.

56. Biederman J, Faraone SV: Attention-deficit hyperactivity disorder. Lancet 2005, 366:237-248

57. Swanson JM, Kraemer HC, Hinshaw SP, Arnold LE, Conners CK, Abikoff HB, Clevenger W, Davies M, Elliott GR, Greenhill LL, et al: Clinical relevance of the primary findings of the MTA: success rates based on severity of ADHD and ODD symptoms at the end of treatment. J Am Acad Child Adolesc Psychiatry 2001, 40:168-179.

58. Molina BS, Hinshaw SP, Swanson JM, Arnold LE, Vitiello B, Jensen PS, Epstein JN, Hoza B, Hechtman L, Abikoff HB, et al: The MTA at 8 years: prospective follow-up of children treated for combined-type ADHD in a multisite study. J Am Acad Child Adolesc Psychiatry 2009, 48:484-500.

59. Pliszka SR: The neuropsychopharmacology of attention-deficit/ hyperactivity disorder. Biol Psychiatry 2005, 57:1385-1390.

60. Wilens TE: Effects of methylphenidate on the catecholaminergic system in attention-deficit/hyperactivity disorder. J Clin Psychopharmacol 2008, 28:546-53.

61. Swanson CJ, Perry KW, Koch-Krueger S, Katner J, Svensson KA, Bymaster FP: Effect of the attention deficit/hyperactivity disorder drug atomoxetine on extracellular concentrations of norepinephrine and dopamine in several brain regions of the rat. Neuropharmacology 2006, 50:755-760.

62. Solanto MV: Neuropsychopharmacological mechanisms of stimulant drug action in attention-deficit hyperactivity disorder: a review and integration. Behav Brain Res 1998, 94:127-152.

63. Biederman J, Spencer TJ: Psychopharmacological interventions. Child Adolesc Psychiatr Clin N Am 2008, 17:439-458.
64. Wang M, Ramos BP, Paspalas CD, Shu Y, Simen A, Duque A, Vijayraghavan S, Brennan A, Dudley A, Nou E, et al: Alpha2A-adrenoceptors strengthen working memory networks by inhibiting CAMP-HCN channel signaling in prefrontal cortex. Cell 2007, 129:397-410.

65. Sallee FR, Lyne A, Wigal T, McGough JJ: Long-term safety and efficacy of guanfacine extended release in children and adolescents with attentiondeficit/hyperactivity disorder. J Child Adolesc Psychopharmacol 2009, 19:215-226.

66. Sallee FR, McGough J, Wigal T, Donahue J, Lyne A, Biederman J: Guanfacine extended release in children and adolescents with attentiondeficit/hyperactivity disorder: a placebo-controlled trial. J Am Acad Child Adolesc Psychiatry 2009, 48:155-165.

67. Stiefel G, Besag FM: Cardiovascular effects of methylphenidate, amphetamines and atomoxetine in the treatment of attention-deficit hyperactivity disorder. Drug Saf 2010, 33:821-842.

68. Stahl SM: Mechanism of action of stimulants in attention-deficit/ hyperactivity disorder. J Clin Psychiatry 71:12-13.

69. Rapoport UL, Gogtay N: Brain neuroplasticity in healthy, hyperactive and psychotic children: insights from neuroimaging. Neuropsychopharmacology 2008, 33:181-197.

70. Konrad K, Neufang S, Fink GR, Herpertz-Dahlmann B: Long-term effects of methylphenidate on neural networks associated with executive attention in children with ADHD: results from a longitudinal functional MRI study. J Am Acad Child Adolesc Psychiatry 2007, 46:1633-1641.

71. Coghill DR, Rhodes SM, Matthews $K$ : The neuropsychological effects of chronic methylphenidate on drug-naive boys with attention-deficit/ hyperactivity disorder. Biol Psychiatry 2007, 62:954-962.

72. Sonuga-Barke EJ: Causal models of attention-deficit/hyperactivity disorder: from common simple deficits to multiple developmental pathways. Biol Psychiatry 2005, 57:1231-1238.

73. Gilbert DL, Wang Z, Sallee FR, Ridel KR, Merhar S, Zhang J, Lipps TD, White C, Badreldin N, Wassermann EM: Dopamine transporter genotype influences the physiological response to medication in ADHD. Brain 2006, 129:2038-2046

74. Faraone SV: Using Meta-analysis to Compare the Efficacy of Medications for Attention-Deficit/Hyperactivity Disorder in Youths. P T 2009, 34:678-694.

75. Kratochvil CJ, Milton DR, Vaughan BS, Greenhill LL: Acute atomoxetine treatment of younger and older children with ADHD: a meta-analysis of tolerability and efficacy. Child Adolesc Psychiatry Ment Health 2008, 2:25.

76. Biederman J, Melmed RD, Patel A, McBurnett K, Konow J, Lyne A, Scherer N: A randomized, double-blind, placebo-controlled study of guanfacine extended release in children and adolescents with attention-deficit/ hyperactivity disorder. Pediatrics 2008, 121:e73-84.

77. Scahill L, Chappell PB, Kim YS, Schultz RT, Katsovich L, Shepherd E, Arnsten AF, Cohen DJ, Leckman JF: A placebo-controlled study of guanfacine in the treatment of children with tic disorders and attention deficit hyperactivity disorder. Am J Psychiatry 2001, 158:1067-1074.

78. Faraone SV, Pucci M, Coghill D: Pharmacotherapy for Attention-deficit Hyperactivity disorder. Eur Psych Review 2009, 2:42-52.

79. Biederman J, Quinn D, Weiss M, Markabi S, Weidenman M, Edson K, Karlsson G, Pohlmann H, Wigal S: Efficacy and safety of Ritalin LA, a new, once daily, extended-release dosage form of methylphenidate, in children with attention deficit hyperactivity disorder. Paediatr Drugs 2003, 5:833-841.

doi:10.1186/1824-7288-36-79

Cite this article as: Curatolo et al:: The neurobiological basis of ADHD. Italian Journal of Pediatrics 2010 36:79. 